\title{
CONSIDERAÇÕES SOBRE O PROCESSO DE RETEXTUALIZAÇÃO PARA LIBRAS DE TEXTOS EM PORTUGUÊS POR GRADUANDOS SURDOS
}

\author{
CONSIDERATIONS ABOUT THE RETEXTUALIZATION \\ PROCESS OF TEXTS IN PORTUGUESE FOR LIBRAS BY DEAF \\ UNDERGRADUATES
}

\section{Maria Lourdilene Vieira Barbosa* Emanoel Barbosa de Sousa**}

RESUMO: O objetivo deste trabalho é discutir o processo de retextualização, para a Língua Brasileira de Sinais (Libras), de textos em português por alunos surdos. Para isso, dentre outros autores, apoiamo-nos teoricamente nas considerações de Travaglia (2013; 1993) e Marcuschi (2010 [2000]) acerca desse processo, entendido, respectivamente, como tradução, numa perspectiva textual, e como transformação de textos na mesma língua. Destacamos ainda as considerações de Karnopp e Quadros (2007) sobre aspectos linguísticos da Língua Brasileira de Sinais. Metodologicamente, analisamos o processo de retextualização em textos sinalizados e gravados em vídeos produzidos por alunos do Curso de Letras-Libras da UFPI, a partir de atividade elaborada na disciplina de Metodologia da Pesquisa em Ciências Humanas, ministrada no segundo período do ano de 2014. A análise dos dados apontou que a modalidade da Língua Brasileira de Sinais exige do tradutor/ intérprete mais do que a habilidade de produzir textos, pois, no processo de tradução para Libras, os elementos linguísticos do português são transformados em elementos linguísticos da Libras. Dessa forma, informações do texto original, escrito em português, reaparecerão transformadas no texto retextualizado, sinalizado em Libras, mas essas informações são organizadas a partir da estruturação linguística da Libras e ressignificadas a partir da interpretação feita pelo surdo do texto escrito em português.

Palavras-chave: tradução; retextualização; Libras.

ABSTRACT: The purpose of this paper is to discuss the retextualization process of texts in Portuguese for the Brazilian Sign Language (Libras) by deaf students. For this, among other authors, we are theoretically based on the considerations of Travaglia $(2013,1993)$ and Marcuschi (2010 [2000]), about the retextualization process, understood, respectively, as a translation, from a textual perspective, and as a transformation of texts in the same language. We also highlight the considerations of Karnopp and Quadros (2007), on linguistic aspects of the Brazilian Sign Language. Methodologically, we analyzed the retextualization process

\footnotetext{
* Universidade Federal do Piauí, Teresina, PI. Brasil. lourdilene@ufpi.edu.br.

** Universidade Federal do Piauí, Teresina, PI. Brasil. emanoel_b.s@ufpi.edu.br
} 
in signalized and videotaped texts produced by undergraduates of Letras-Libras Course of UFPI, from an activity performed in the Methodology of Human Sciences Research discipline, given in the second period of 2014. The analysis of data indicated that the modality of the Brazilian Sign Language requires of the translator/interpreter, more than ability to produce texts, because, in translation process for Libras, the linguistic elements of portuguese are transformed in linguistic elements of the Libras. Thus, the information from the original text, written in Portuguese, will reappear transformed into the retextualized text, signalized in Libras, but this information is organized from the linguistic structure of the Libras and resignified from the deaf interpretation of the original text written in portuguese.

Keywords: translation; retextualization; Libras.

\section{INTRODUÇÃO}

A Língua Brasileira de Sinais (Libras) é a segunda língua oficial do Brasil, utilizada principalmente para a comunicação social entre sujeitos surdos, nas mais diversas situações de interação cotidianas. Na escola formal, além de Libras, o aluno surdo deve ser estimulado a desenvolver habilidades de leitura e escrita de textos em português. Sobretudo no contexto escolar, no processo de educação de surdos, é comum que essas duas línguas estejam sempre sendo colocadas em relação.

Neste artigo, tecemos nossas considerações, a partir de uma análise de natureza descritiva e interpretativa, de estratégias de retextualização utilizadas por estudantes surdos em nível de graduação, vinculados ao curso de Licenciatura em Letras-Libras, da Universidade Federal do Piauí, sobre uma atividade de retextualização de um texto escrito em português para Língua Brasileira de Sinais.

Para nossas considerações iniciais, partimos do seguinte questionamento: que estratégias de retextualização são mais comumente utilizadas por alunos surdos na retextualização de textos escritos em português para Libras? A partir dessa questão central, surgem outras questões secundárias: Como se dá a construção de significação no texto retextualizado pelo surdo? Quais elementos linguísticos principais da Libras são utilizados na construção do texto retextualizado?

Pensamos essas questões pelo fato de que, enquanto professores de alunos surdos, na universidade, nós vemos que os alunos surdos precisam participar de atividades que envolvem a leitura de textos em português em várias situações. Por outro lado, esses mesmos alunos podem, evidentemente, utilizar a Língua Brasileira de Sinais como forma de expressar a interpretação feita na leitura de textos em português.

Desde o início dos nossos estudos sobre educação de surdos e, consequentemente, sobre Libras, chamou-nos a atenção o processo de "passagem" 
tanto do texto em português escrito para língua de sinais, como a construção do texto em português oral, pelo intérprete, a partir do que é sinalizado pelo surdo. Observando essa complexa rede comunicativa, vimos que tínhamos: 1) $\mathrm{O}$ texto em português escrito apresentado pelo professor; 2) $\mathrm{O}$ texto sinalizado produzido pelo aluno surdo e relacionado diretamente ao primeiro, uma vez que este consiste na interpretação do surdo feita a partir daquele; e 3) $\mathrm{O}$ texto com a interpretação que o intérprete faz do que é sinalizado pelo surdo, que também se liga ao primeiro texto, mas está mais diretamente relacionado ao segundo.

Dessa forma, neste trabalho, partimos do entendimento de que as estratégias de retextualização utilizadas na retextualização do texto escrito em português para Libras estão diretamente relacionadas com a estrutura da língua alvo, uma vez que a estrutura gramatical da língua alvo condiciona o processo de elaboração do texto sinalizado feito pelo sujeito. Consideramos ainda que, em relação ao sentido dado ao texto, o resultado da retextualização do texto em português escrito para Libras depende da interpretação que o sujeito faz do texto a ser retextualizado. Assim, o sentido do texto em português é mais preservado no texto em Libras quando o sujeito conhece bem as duas línguas envolvidas.

Portanto, temos como objetivo geral analisar o processo de retextualização para Libras de textos escritos em português, por alunos surdos. A partir do objetivo geral, elegemos os específicos: 1) Identificar as estratégias de retextualização utilizadas por alunos surdos, na retextualização de textos escritos em português para Libras; 2) Comparar a construção de significação de textos em português e seu "correspondente" retextualizado em Libras; e 3) Explicar a adaptação/transformação de textos escritos em português e textos sinalizados em Libras retextualizados, com base na estrutura linguística do português e da Libras.

Para nossas considerações, seguimos teoricamente, dentre outros autores, o que é proposto por Travaglia $(1993 ; 2013)$, por Marcuschi (2000) e por VieiraBarbosa (2015), sobre o processo de retextualização, e Karnopp e Quadros (2007), sobre aspectos linguísticos de Língua Brasileira de Sinais. Nossas considerações acontecem a partir de alguns textos, que formam o nosso corpus de análise, composto por um resumo acadêmico, quatro vídeos com a tradução/retextualização para Libras do resumo acadêmico e um texto feito pelo intérprete a partir da sinalização feita por um dos sujeitos surdos.

Este estudo se justifica pela sua proposta de investigar sobre a compreensão escrita de alunos surdos, a partir da análise descritivo-interpretativa do processo de retextualização de textos escritos em português, na retextualização para a Língua Brasileira de Sinais. Acreditamos, dessa forma, que as reflexões e discussões 
que desenvolvemos aqui contribuirão para ampliar o entendimento do processo de leitura e interpretação de alunos surdos. A partir do estudo das estratégias de retextualização utilizadas pelos sujeitos na tradução para Libras dos textos em português, será possível pensarmos, posteriormente, em estratégias pedagógicas para o melhor desenvolvimento das habilidades de leitura e escrita em sala de aula, a fim de contribuir com a efetiva inclusão de sujeitos surdos na escola formal, seja em nível básico ou em nível superior.

\section{CONTEXTUALIZAÇÃO TEÓRICA: O PROCESSO DE RETEXTUALIZAÇÃO}

Nesta seção, apresentamos os autores e as principais definições teóricas que seguimos para as considerações que fazemos neste trabalho. Já nesta parte do artigo, discutimos essas definições, relacionando-as, na medida do possível, ao que nos propomos como objetivo de pesquisa.

Existem muitos trabalhos com o processo de retextualização sendo utilizado como uma ferramenta pedagógica para o ensino de leitura e compreensão e de produção textual escrita, em língua portuguesa, no ensino básico e até mesmo na graduação. Ressaltamos as contribuições de Abasse (2008), que analisou a produção do resumo escolar resultante da atividade de retextualização; Malta (2008), com o estudo sobre a retextualização no conto tradicional e a investigação sobre o refinamento de narrativas orais produzidas pelos alunos de diferentes grupos sociais; Militão (2007), que trabalha com as produções escritas (anotações) de alunos de graduação, a partir das explicações do professor em sala de aula; Mata (2009) e Marega (2009), que analisam processos referenciais na retextualização de textos acadêmicos; e Silva (2013), que desenvolveu um estudo sobre retextualização, analisando a exposição oral acadêmica de alunos de graduação.

No âmbito dos estudos sobre Libras, as pesquisas que utilizam a noção de retextualização discutem mais o processo de tradução, como é feito em Souza (2010), que descreve a atividade tradutória de um texto escrito em português para um texto sinalizado em Libras, analisando as performances desenvolvidas por uma surda tradutora-atriz. A pesquisa de Souza considera o processo de retextualização no âmbito da tradução e o verifica relacionado a teorias da tradução e, notadamente, a outros aspectos e categorias de análise além do que se verifica em relação à noção de retextualização.

Diferentemente de Souza (2010), que aborda especialmente questões de tradução, inclusive analisando a tradução do intérprete surdo, nossas considerações repousam sobre o aluno surdo da graduação, que precisa desenvolver na universidade 
o conhecimento acadêmico, a partir do conhecimento linguístico em duas línguas. Nesse sentido, é de fundamental importância que esse desenvolvimento possa acontecer de maneira efetiva, e, para tanto, pesquisas precisam ser desenvolvidas a fim de que sejam apontados caminhos e alternativas que otimizem o trabalho do professor, ao ensinar, e do aluno surdo, ao aprender. Ademais, a maior dificuldade do aluno surdo na escola formal é linguística, uma vez que a educação bilíngue precisa fazer parte da educação do surdo desde o ensino infantil, o que não é ainda uma realidade do contexto brasileiro.

Já desenvolvemos anteriormente, em Vieira-Barbosa (2015), uma pesquisa sobre o processo de retextualização em webnotícias, em que analisamos o processamento da informação neste gênero. A partir de nossa experiência em analisar casos que envolvem a retextualização em diferentes gêneros textuais escritos, numa mesma língua, e do nosso conhecimento de que este processo também é analisado na perspectiva da tradução, vimos a possibilidade de utilizarmos a retextualização como metodologia em sala de aula, na educação de surdos, e também para a pesquisa, analisando como o processo ocorre efetivamente a partir de produções textuais concretas de surdos, como fazemos neste trabalho.

\subsection{A retextualização como tradução entre línguas e como transformação de textos na mesma língua}

Segundo Marcuschi (2010 [2000]), a retextualização está presente em várias atividades cotidianas diárias, nas quais interagimos uns com os outros e reformulamos, transformamos, adaptamos, enfim, retextualizamos textos em diferentes modalidades da língua. Nesse sentido, para este autor, a retextualização consiste na transformação de um novo texto a partir de um texto preexistente, podendo ocorrer da modalidade oral para a modalidade escrita, ou vice-versa, bem como da modalidade oral para a oral e da escrita para a escrita.

Antes de Marcuschi, Travaglia (2013) ${ }^{1}$ utiliza o termo retextualização, para se reportar à tradução entre línguas, numa abordagem textual, partindo do princípio, compartilhado pelas teorias tradicionais e modernas sobre tradução, de que não traduzimos línguas, nós traduzimos textos. Segundo a autora, cada tradução corresponde a um evento singular na medida em que cada texto é único e individualizado, e a tradução também tem um caráter único e individual. A proposta

1. Essa publicação é resultante da pesquisa desenvolvida por Travaglia, no seu Doutorado em Tradução, concluído em 1993. 
de Travaglia, com a tradução/retextualização, desloca o foco de observação da tradução para o fato de que ao traduzir:

o tradutor está na realidade acionando todos os elementos que conferem textualidade a um texto e que foram anteriormente acionados pelo produtor do texto original, com a diferença de que, manejando uma outra língua, o tradutor estará de certa forma manejando outros elementos ou até os mesmos elementos sob perspectivas diferentes (p. 80-81).

Afirmar isso significa entender que o processo de tradução envolve uma nova produção textual, sendo que, no processo de tradução, os elementos do texto original voltam, porém, regidos por outras regras, uma vez que pertencem a uma outra língua e a uma outra cultura. No caso da tradução/retextualização para Libras de textos em português por alunos surdos, os "tradutores" levam em conta a organização e a estrutura da sua língua materna.

Travaglia (2013) se reporta à retextualização como tradução, considerando mecanismos envolvidos na textualização, segundo Beaugrande e Dressler (1981). Dessa forma, mecanismos textuais devem ser levados em conta como etapas do processo tradutório, que precisa considerar tanto fatores de retextualização como de coerência textuais, envolvendo, portanto, conhecimentos linguísticos, de mundo e partilhados, informatividade, focalização e inferência, relevância, fatores pragmáticos, situacionalidade, intertextualidade, intencionalidade e aceitabilidade.

Logo, traduzir consiste numa tarefa complexa que além de línguas e textos, está relacionada a práticas sociais e culturais da língua original do texto a ser traduzido e da língua alvo, em que será construído o texto retextualizado. Se pensarmos esses aspectos considerando a língua portuguesa e a Língua Brasileira de Sinais, veremos que os elementos do texto original, escrito em português, reaparecerão no texto retextualizado, sinalizado em Libras. Porém, esses mesmos elementos são reorganizados, porque será levado em conta a estruturação linguística da Libras, que tem organização morfológica e sintática própria e não é uma língua oral, como o português. Ademais, o texto retextualizado apresentará a ressignificação do texto original escrito em português, segundo a interpretação feita pelo surdo, que tem a Libras como língua materna e o português apenas como segunda língua.

Atualmente, já é de conhecimento comum o reconhecimento de que a Libras, como as demais línguas de sinais, tem um código linguístico complexo e completo. De acordo com Karnopp e Quadros (2007), as características das línguas de sinais permitem identificá-las com as demais línguas naturais. Uma língua natural consiste numa realização específica da faculdade de linguagem, com um sistema abstrato de regras finitas, que permitem a produção de um número ilimitado de frases. A 
utilização efetiva desse sistema, com um fim social, permite a comunicação entre os sujeitos.

As autoras argumentam que as palavras faladas representam para as línguas orais o que os sinais representam para as línguas de sinais, sendo as frases da língua representáveis em termos de uma sequência dessas unidades. Os sinais não são imagens, mas símbolos abstratos complexos, com uma complexa estrutura interior. Cada sinal apresenta pelo menos três unidades independentes, que são a localização, a configuração de mãos e o movimento, sendo que cada unidade possui um número limitado de combinações (KARNOPP e QUADROS, 2007).

Embora tenhamos partido da perspectiva de Travaglia (2013), acerca do processo de retextualização como tradução, é fundamental considerarmos o entendimento de Marcuschi (2010 [2000]) de retextualização como transformação, na construção de um texto a partir de outro, permanecendo na mesma língua. É importante trazermos Marcuschi para esta discussão, porque entendemos que a organização visual espacial da Língua Brasileira de Sinais requer do tradutor mais do que a habilidade de produzir textos, uma vez que, no processo de retextualização para Libras, os elementos linguísticos do português (as palavras escritas) são transformados em elementos linguísticos da Libras (sinais), e além da transposição de um texto de uma língua para outra, estão envolvidas estratégias textuais, no mesmo sentido apresentado por Marcuschi.

Então, muito embora estejamos falando da passagem de um texto de uma língua para outra, entendemos que essa passagem estaria muito mais ligada à noção marcuschiana de retextualização. Dizemos isso porque, ao falarmos de tradução em qualquer língua, feita por um surdo, para a Libras, ainda que numa perspectiva textual, estamos falando de um processo diferente de uma tradução de textos entre línguas orais/escritas. Isso porque, no caso da Libras, especificamente, o processo envolve uma "tradução" de um texto de uma língua oral/escrita para um texto de uma língua visual e espacial. Nesse caso, a "tradução" se aproxima mais de uma transformação do texto original para o retextualizado, haja vista que o surdo interpreta o texto em português e o reproduz a partir de sinais "equivalentes" na sua língua. Na retextualização, é possível a identificação de estratégias utilizadas, para a construção do texto a partir de um primeiro.

Marcuschi (2010 [2000]), em "Da Fala para a Escrita: atividades de retextualização", reporta-se ao processo de retextualização, a partir de um entendimento mais amplo do que o que é apresentado por Travaglia, em sua tese de Doutorado. Marcuschi examina especificamente, neste trabalho, mecanismos envolvidos na transformação da oralidade em escrita. $\mathrm{O}$ autor analisa casos de 
textos orais retextualizados, em situações concretas de uso da língua portuguesa, para textos escritos. No Quadro 1, a seguir, adaptado de Marcuschi, vemos que entre fala e escrita é possível que haja diferentes combinações para ocorrência de retextualização:

Quadro 1. Possibilidades de retextualização

\begin{tabular}{|c|c|c|c|c|}
\hline \multicolumn{5}{|c|}{ Possibilidades de retextualização } \\
\hline 1. Fala & - & Escrita & $\rightarrow$ & (entrevista oral - entrevista impressa) \\
\hline 2. Fala & - & Fala & $\rightarrow$ & (conferência - tradução simultânea) \\
\hline 3. Escrita & - & Fala & $\rightarrow$ & (texto escrito - exposição oral) \\
\hline 4. Escrita & - & Escrita & $\rightarrow$ & (texto escrito - resumo escrito) \\
\hline
\end{tabular}

Fonte: Adaptado de Marcuschi (2010 [2000], p. 48).

O autor argumenta que a retextualização está presente diariamente em situações que vivemos e que já são automatizadas em relação às reformulações de textos, que se dão a partir de diferentes gêneros, níveis linguísticos e estilos. Sempre que repetimos ou relatamos a fala de alguém, nas mais diferentes situações sociais de uso linguístico, até mesmo as mais corriqueiras, transformamos, reformulamos, recriamos e modificamos uma fala em outra.

A partir das considerações de base de Marcuschi (2010 [2000]) de retextualização também como transformação de um texto a partir de outro na mesma língua, várias pesquisas acadêmicas começaram a ser desenvolvidas, vinculadas, especialmente ao âmbito educacional, em que, de alguma forma, investiga-se o processo de leitura e produção de textos. Dessa forma, os investigadores, considerando a possibilidade de haver retextualização do oral para o escrito e vice-versa, bem como entre textos escritos, formularam variações diversas dessas possibilidades, desenvolvendo pesquisas em diferentes gêneros textuais.

Em linhas gerais, o processo de retextualização, portanto, é entendido como decorrendo explicitamente de informações que vêm de um texto específico, oral ou escrito, que serve como fonte de informações, mas essas informações são, sobretudo, transformadas, no texto retextualizado. A Figura 1, a seguir, foi apresentada por Vieira-Barbosa (2015), em sua tese de Doutorado, para ilustrar o processo de retextualização: 
Figura 1. Esquema do processo de retextualização

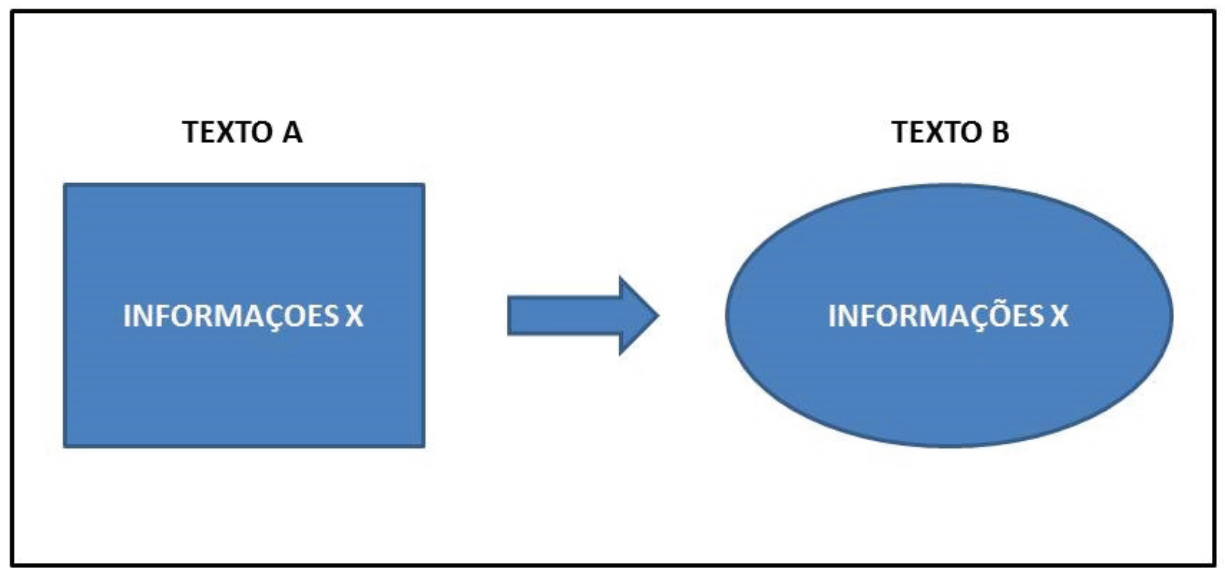

Fonte: Vieira-Barbosa $(2015$, p. 87).

De acordo com a autora, "o texto A serve como base informativa [...] para a construção do texto $\mathrm{B}[\ldots], \operatorname{logo}$, a existência do texto $\mathrm{B}$ está condicionada à existência prévia do texto $\mathrm{A}$, que é aquele tomado como base informativa no processo de retextualização" (VIEIRA-BARBOSA, 2015, p. 87). É importante ressaltar, mais uma vez, que o processo de retextualização não envolve fatores apenas de ordem textual, uma vez que

nesse processo de construção de um texto a partir de outro, podemos ter uma nova situação de comunicação, e a "mesma" informação que aparece no texto-base e no texto retextualizado pode funcionar socialmente de maneira diferente em razão da situação comunicativa de um e de outro texto. (VIEIRA-BARBOSA, 2015, p. 87)

Conforme argumenta Vieira-Barbosa (2015), seguindo Marcuschi (2010 [2000]), as adaptações necessárias, na construção de um texto a partir de outro, são feitas a partir das contingências da situação de interação. Assim, podemos aliar o processo de retextualização à finalidade comunicativa da interação. Neste ponto, a noção de gênero textual aparece como a força que direciona a forma e a função do texto.

Por outro lado, para pensarmos sobre o processo de transformação de um texto escrito em português para um texto sinalizado em Libras, considerando a noção de retextualização, não podemos abandonar o que é apresentado em Travaglia (2013), uma vez que estamos falando da passagem de um texto de uma língua para outra língua. No entanto, precisamos considerar ainda Marcuschi (2010 
[2000]), porque entendemos que, nessa retextualização, existem aspectos tanto de tradução (ainda que numa perspectiva textual) como de contingências próprias da retextualização como transformação, conforme é apresentado em Marcuschi.

Assim, na análise dos textos, consideramos estratégias de retextualização já analisadas em várias pesquisas que partem das considerações de base de Marcuschi (2010 [2000]), como na pesquisa de Vieira-Barbosa (2015). As estratégias são:

a. Acréscimo: em que o locutor insere, adicionando informações no texto retextualizado, a partir do que é considerado pelo texto-fonte.

b. Eliminação: em que o locutor, basicamente, apaga, eliminando informações do texto-fonte e selecionando somente aquelas julgadas como importantes e/ou relevantes de permanecerem no texto retextualizado.

c. Reordenação: em que o locutor reorganiza, reordenando as informações do texto retextualizado, normalmente considerando elementos estilísticos e composicionais condicionados pelo gênero textual.

d. Substituição: em que o locutor substitui expressões sintáticas e/ou lexicais do texto-fonte na reordenação de informações.

Um aspecto fundamental que precisa ser levado em consideração para o que objetivamos com este trabalho, é que nem Travaglia, quando estudou a retextualização como tradução em textos escritos, nem Marcuschi, quando ampliou a noção para transformações entre textos na mesma língua em modalidades distintas, da oral para a escrita, especificamente, nem mesmo Vieira-Barbosa (2015), quando aplicou essa noção, numa pesquisa em produções textuais entre gêneros textuais escritos diferentes, pensaram (diretamente) o fenômeno da retextualização em relação às línguas de sinais.

No entanto, para pensar a noção de retextualização em qualquer uma de suas possibilidades, precisamos considerar fundamentalmente o posicionamento teórico dos autores que pensaram inicialmente sobre o processo. São as considerações desses autores que nos possibilitarão entender o processo de retextualização acontecendo em situações ainda não analisadas em pesquisas linguísticas, sobretudo quando relacionamos a retextualização considerando língua de sinais.

Logo, as reflexões, discussões e análises que empreendemos aqui, neste trabalho, são resultantes da nossa experiência com o estudo do processo de retextualização e do nosso entendimento de que é possível sim estender essa 
noção teórica no âmbito dos estudos linguísticos de Língua Brasileira de Sinais. Entendemos que as sinalizações feitas por sujeitos surdos, em suas mais diversas situações de comunicação, são produções textuais concretas passíveis de análise e sistematização. Para tanto, quando se trata de situações em que é possível perceber o processo de retextualização, é preciso considerar as contingências próprias da formulação de enunciados, bem como as especificidades relacionadas à língua do texto original e à língua alvo.

\section{PROCEDIMENTOS METODOLÓGICOS DO TRABALHO}

Nesta seção, apresentamos o caminho que percorremos, do ponto de vista metodológico, para as considerações feitas neste artigo, o modo como se deu a produção dos dados que analisamos e os procedimentos que adotamos para a análise e discussão desses dados.

\subsection{Motivação e contextualização da pesquisa}

A motivação deste trabalho se deu pela nossa aprovação em concurso público para a área de Linguística, no curso de Licenciatura em Letras-Libras, da Universidade Federal do Piauí, que tem como público-alvo estudantes surdos e ouvintes. O curso tem uma proposta inclusiva bilíngue e, portanto, em nível de graduação, exige-se, naturalmente, do aluno surdo a habilidade de se comunicar em Libras e de ler e compreender textos escritos em português, bem como de escrever textos em português. O conhecimento linguístico, tanto de Libras como de português escrito, deve ser aprofundado durante o curso de graduação, mas o aluno surdo já deve chegar à universidade sabendo se comunicar nas duas línguas.

Nesse sentido, de acordo com a proposta de cada disciplina, o professor normalmente usa textos escritos em português, uma vez que o português é a língua em que se produz quase todo o material didático disponível. Logo, é importante que o professor entenda a construção da interpretação de textos em português por surdos e como esses textos são "transformados" para Libras por esses sujeitos, como forma de se trabalhar de maneira mais efetiva os conteúdos e, inclusive, de aprofundar as habilidades de leitura e escrita em português desses alunos.

Sabemos que cursos, em nível de graduação, de qualquer instituição de ensino superior do Brasil exigem do aluno a leitura eficiente de textos acadêmicos em diferentes gêneros, bem como a produção textual escrita em português, na modalidade padrão desta língua. Logo, o próprio documento que regulamenta o 
curso de Licenciatura em Letras-Libras da UFPI, Projeto Pedagógico do Curso (PROJETO, 2014), parte do pressuposto de que os alunos surdos têm conhecimento de Libras e de português e que eles sabem fazer relação entre as duas línguas de maneira satisfatória.

Dessa forma, durante o curso, caberia ao professor "formar" o aluno para ser professor, desenvolvendo tanto habilidades de reflexão teórica e metalinguística sobre o idioma Libras, com disciplinas sobre língua de sinais e sobre linguística teórica e aplicada, e sobre o fazer pedagógico, com disciplinas sobre aspectos teóricos e práticos voltados para a docência e educação, como normalmente é feito em outros cursos de Letras. Ademais, o aluno de Letras-Libras ainda é apresentado aos textos e práticas socioculturais recorrentemente utilizadas no ambiente acadêmico, uma vez que, na universidade, o acadêmico precisa desenvolver o conhecimento acadêmico, que se relaciona com toda a conjuntura que envolve o meio universitário.

Porém, a realidade que se tem, em nível de Piauí, é bastante diversa daquilo que é assegurado legalmente pelo Decreto Federal 5626/05, em que o bilinguismo é apontado como a saída mais eficiente para a educação de surdos. Pesquisas acadêmicas já realizadas em torno da educação de surdos também defendem esse pensamento.

Parte dos alunos surdos que, atualmente, chega à graduação em Letras-Libras da UFPI ainda não conhece a língua portuguesa, na sua modalidade escrita. Logo, o professor de linguística, por exemplo, não tem condições de apenas chegar em sala de aula e trabalhar conteúdos, a fim de desenvolver nos alunos surdos e ouvintes habilidades de reflexão metalinguística, utilizando a Libras e textos escritos em português.

No Piauí, apenas atualmente é que algumas escolas de ensino básico, com uma proposta inclusiva, têm estrutura mínima para receber um surdo. Essas escolas oferecem intérpretes de línguas de sinais, para acompanhar esse aluno durante às aulas. No entanto, são espaços que ainda apresentam inúmeras limitações, uma vez que apenas a presença do intérprete em sala de aula não garante a inclusão efetiva do surdo nem o seu desenvolvimento educacional. Diante desse cenário, o conhecimento de língua portuguesa, em sua modalidade escrita, que deve ser desenvolvido desde a educação infantil, passando pelo ensino básico, não acontece eficientemente, uma vez que ainda não existe um acompanhamento especializado dos alunos surdos nesse período.

Dessa forma, esses alunos saem do ensino básico e entram na universidade sem conseguir ler e escrever em língua portuguesa de forma minimamente satisfatória. 
Infelizmente, a maioria dos estudantes que já passaram por toda a educação básica traz a deficiência de um sistema educacional defasado que, dentre outros graves aspectos, não prepara o aluno para entrar na universidade.

\subsubsection{Os dados de pesquisa e o desenvolvimento da análise}

A pesquisa que apresentamos aqui foi pensada a partir de material produzido por alunos surdos em atividades desenvolvidas durante aulas na graduação. Enquanto professores da disciplina de Metodologia da Pesquisa em Ciências Humanas, que é ofertada para o primeiro período do curso de Licenciatura em Letras-Libras da Universidade Federal do Piauí, precisamos inserir academicamente alunos recémchegados na universidade, em uma comunidade que, dentre outras especificidades, produz textos que participam de gêneros textuais que circulam e estão diretamente relacionados ao que se faz no meio acadêmico.

Assim, uma das atividades desenvolvidas ao longo do semestre foi solicitar dos alunos a retextualização de um resumo acadêmico. Essa atividade foi desenvolvida de acordo com as etapas a seguir:

1) Trabalhamos o gênero resumo acadêmico em sala de aula, mostrando e explicando sobre normas de submissões de trabalhos (resumos), em eventos científicos de diferentes áreas do conhecimento e, também, analisando resumos acadêmicos retirados de cadernos de resumos de eventos científicos.

2) Dividimos os alunos, em pequenos grupos formados por surdos e ouvintes, para eles analisarem resumos acadêmicos, buscando identificar e refletir sobre diferentes passos retóricos que compõem o texto, reconhecendo informações sobre objetivos, referencial teórico, metodologia, corpus de análise, resultados e conclusões.

3) Trabalhamos as normas da Revista Brasileira de Vídeo-Registro em Libras², da Universidade Federal de Santa Catarina, apontando para especificidades do

2. A Revista Brasileira de Vídeo-Registro em Libras (http://revistabrasileiravrlibras.paginas.ufsc.br/) é um periódico especializado em línguas de sinais e publica artigos científicos em Libras em formato de vídeo. A revista propõe uma normatização de artigos acadêmicos em Libras, que toma como base as características formais do gênero artigo científico na modalidade escrita e vídeos já produzidos por estudantes, para a realização de atividades propostas pelos professores, na universidade. Então, seguindo os periódicos existentes nas diversas áreas do conhecimento, a Revista Brasileira de Vídeo-Registro em Libras possui corpo editorial, normas de submissão, faz chamadas públicas para a publicação de artigos etc.. 
artigo acadêmico, que, seja escrito ou sinalizado, tem um caráter formal e visa à objetividade.

4) Informamos que seria feita uma atividade, valendo uma nota da disciplina, em que os alunos deveriam retextualizar um resumo acadêmico escrito em português para Libras, realizando a gravação de um vídeo que deveria seguir as normas da Revista Brasileira de Vídeo-Registro. As normas da revista visam a, de alguma forma, transpor para o plano visual-espacial aspectos formais e estilísticos que envolvem a produção de artigos científicos. ${ }^{3}$

5) Apresentamos o resumo acadêmico que seria retextualizado e pedimos para que fosse feita a leitura atenta do texto, de modo que já se pensasse acerca dos sinais em Libras que melhor corresponderiam ao sentido das palavras do resumo em português. Nesta etapa, alguns alunos surdos pediram ajuda dos ouvintes para leitura do texto em português e outros fizeram a leitura apenas com o auxílio de dicionário.

6) Trabalhamos a leitura e interpretação do texto a ser retextualizado, para escolha dos sinais que melhor apresentassem ou que mais se aproximassem do sentido do texto original, de acordo com o ponto de vista e do conhecimento linguístico dos alunos.

7) Gravamos o vídeo-registro, de modo que os alunos cuidaram tanto da parte conteudística e técnica, quanto do material que seria utilizado, como camisetas em cores específicas, câmeras, fundo e iluminação etc.

Como corpus de análise, temos quatro vídeos produzidos por alunos surdos a partir da atividade descrita anteriormente. Como o suporte deste trabalho nos limita ao âmbito gráfico, utilizamos uma "tradução literal", que reproduz a significação em português do que é sinalizado em Libras, sinal por sinal. Embora existam perdas da complexidade comunicativa dos vídeos, pelo fato de o visual-espacial estar simplificado e limitado a palavras escritas, esse procedimento metodológico nos auxilia na análise dos dados e atende aos objetivos estabelecidos neste trabalho especificamente.

3. Dentre outras normas, a Revista Brasileira de Vídeo Registro em Libras exige que o sinalizador use camisetas em modelo e cor específicos de acordo com a parte do texto (se título, corpo do texto ou citação direta) e com a sua cor de pele, que utilize iluminação, cor de fundo e enquadramento do vídeo determinados etc.. A revista com as normas de publicação está disponível para consulta pública no site: http://revistabrasileiravrlibras.paginas.ufsc.br/. 
Para as considerações que fazemos neste artigo, a análise dos dados propriamente analisa de modo comparativo: a) o resumo acadêmico escrito em português; b) a "tradução literal" do vídeo sinalizado por um surdo que teve ajuda de ouvintes para a leitura do texto fonte e para a escolha dos sinais em Libras; c) a "tradução literal" do vídeo sinalizado por um surdo que não teve ajuda de ouvintes para a leitura do texto-fonte a para a escolha dos sinais em Libras; d) e, ainda, tecemos considerações sobre o texto com a interpretação feita por um intérprete de língua de sinais, ao visualizar um dos vídeos e interpretá-lo, simultaneamente, sem ter visto, com antecedência, o resumo acadêmico em que o surdo se baseava.

\section{A RETEXTUALIZAÇÃO SINALIZADA EM LIBRAS DE TEXTOS ESCRITOS EM PORTUGUÊS FEITA POR ESTUDANTES SURDOS DA GRADUAÇÃO}

Nesta seção, com base nas orientações teóricas sobre retextualização a que nos filiamos e que apresentamos na seção 2, fazemos a análise de dados deste trabalho, que são textos sinalizados por surdos da graduação, que foram retextualizados a partir da leitura e interpretação de um texto escrito em português. Discutimos ainda sobre o conteúdo do texto elaborado por um intérprete de língua de sinais a partir da visualização de um dos vídeos que continha uma das retextualizações.

Quando discutimos a orientação teórica, deste trabalho, na seção 2, dissemos que, ao vermos o processo de retextualização como uma tradução na perspectiva textual, segundo a concepção de Travaglia (2013), devemos considerar diversas variáveis relacionadas mesmo à própria construção da textualização. Assim, retextualizar consistiria, basicamente, textualizar novamente, considerando contingências de formulação da língua alvo, bem como aspectos socioculturais que também estariam ligados à coerência do texto e, consequentemente, à construção de significação.

Esse entendimento permite que vejamos o texto sinalizado pelo aluno surdo como o produto de uma língua com níveis linguísticos, como morfologia, sintaxe, semântica etc., próprios que, por sua vez, são bastante diversos dos níveis linguísticos do português. Isso condiciona sobremaneira a composição textual em uma e na outra língua, uma vez que a "mesma realidade" é recortada diferentemente e representada diferentemente pela língua. Mesmo sendo vista na perspectiva da tradução (TRAVAGLIA, 2013), a retextualização é entendida como uma nova composição textual, feita segundo normas e valores linguísticos e socioculturais característicos da língua alvo, que, neste caso, é ainda mais peculiar por se tratar de uma língua visual-espacial. 
Conforme já discutimos na seção 2, quando falamos em retextualização, devemos considerar o que é apresentado em Marcuschi (2010 [2000]), que é apresentada por este autor como uma transformação, em que se produz um texto a partir das informações de um primeiro, permanecendo na mesma língua. Estratégias de retextualização analisadas em trabalhos acadêmicos já desenvolvidos a partir da noção marcuschiana de retextualização, como a eliminação, o acréscimo, a substituição e a reordenação, apontam para um caminho de análise de dados que nos permite visualizar no texto retextualizado as transformações realizadas nas informações do texto original. Essas estratégias são utilizadas na análise que fazemos neste trabalho.

\subsection{Análise dos dados}

Como dissemos na seção 4, os dados que analisamos neste trabalho são resultantes de uma estratégia pedagógica que desenvolvemos a partir de uma atividade realizada com alunos de graduação, em que, após serem trabalhados aspectos de forma e conteúdo do gênero resumo acadêmico, foi solicitado dos alunos a retextualização de um resumo acadêmico, segundo as normas da Revista Brasileira de Vídeo Registro em Libras.

Por sabermos que os alunos tinham dificuldades com a leitura de textos em português, escolhemos um resumo que, embora utilizasse uma linguagem acadêmica, considerada pelos alunos de mais difícil leitura, tratava do ensino de português como segunda língua para crianças surdas. Entendemos que um texto com um tema voltado especialmente para a vivência dos alunos poderia leva-los a uma leitura mais motivada e, consequentemente, mais eficaz.

O quadro 2, a seguir, mostra o resumo acadêmico apresentado para a atividade de retextualização: 
Quadro 2. Resumo acadêmico escrito em português e retextualizado por alunos surdos de graduação

\author{
ADEQUAÇÃO DO ENSINO DO PORTUGUÊS COMO L2 NAS CRIANÇAS SURDAS: \\ UM DESAFIO A SUPERAR/ENFRENTAR
}

Marisa Dias Lima

RESUMO: A história do povo surdo revela que por muitos séculos de existência, os aspectos educacionais têm sido elaborados numa perspectiva dos ouvintes e não dos surdos que, quase sempre, são ignorados e desvalorizados como sujeitos profissionais que podem contribuir a partir de suas capacidades inerentes e de sua diferença: a de ser surdo. Desta maneira, a "interação/ inclusão" de sujeitos surdos nas escolas, tendo-se a língua oral e não a LIBRAS como principal forma de comunicação, faz-nos questionar se o seu conteúdo metodológico ouvintista significa integrar o surdo realmente. Na verdade, os seus conteúdos desenvolvidos são basicamente uma suposição, "adaptação" forçada para surdos. Assim, este trabalho elege como objeto de estudo uma proposta das utilizações de estratégias pedagógicas adequadas no ensino de português como segunda língua para uma efetiva inserção dos surdos no processo escolar, dinamizando por meio de recursos específicos o processo ensino-aprendizado dos surdos.

Palavra-chave: LIBRAS, Português L2, Estratégias Pedagógicas, Aprendizagem.

Fonte: LIMA, M. D. Adequação do ensino do português como 12 nas crianças surdas: um desafio a superar/enfrentar. Disponivel em: $<$ http://2014.revistaintercambio.net.br/24h/pessoa/temp/ anexo/1/416/744.pdf >. Acesso em: 02/11/2014.

Conforme o que vemos no Quadro 2, o resumo acadêmico é a parte inicial de um artigo científico que discute desafios a serem enfrentados ou superados no ensino de língua portuguesa como segunda língua para crianças surdas. A autora compõe o texto do resumo, basicamente, reportando-se às dificuldades mais gerais que vêm sendo enfrentadas ao longo da história conhecida da educação de surdos. $\mathrm{O}$ texto diz que os sujeitos surdos sempre foram colocados à margem da sociedade e, de alguma forma, "forçados" a aprender a língua oral, em que os sujeitos ouvintes se comunicam, em detrimento da língua de sinais, que seria a língua apropriada para quem não pode ouvir. Dessa forma, a "inclusão" do aluno surdo na escola é feita a partir da supremacia "ouvintista" que, dentre outras práticas, impõe a língua oral para o surdo. De um modo geral, o resumo apresenta apenas uma contextualização acerca da temática a ser abordada no artigo e um objetivo ao final do texto.

De posse de cópia do texto, os estudantes fizeram a leitura atenta do resumo e produziram, a partir de então, os seus textos, seguindo os critérios elencados para a atividade. Uma das produções dos surdos resultante dessa atividade aparece na 
tradução literal em português que apresentamos no Quadro 24, a seguir. Essa forma de apresentação dos dados foi feita para preparar esses dados para o tipo de análise que desenvolvemos aqui, de acordo com as possibilidades do suporte que temos a disposição, e para atender aos objetivos que temos com este trabalho.

\section{Quadro 3. Tradução literal do texto sinalizado pelo sujeito surdo 1}

TEMA (TÍTULO) CRIANÇAS SURDAS ENSINAR PORTUGUÊS L2 AQUISIÇÃO DIFÍCIL MAS EVOLUIR CONSEGUIR POSSÍVEL

PESSOA ESCREVER NOME M-A-R-I-S-A D-I-A-S L-I-M-A

NOME INTÉRPRETE -...-

PESQUISAR SURDO ENSINO PASSADO HISTÓRIA ATÉ HOJE MOSTRA O QUE ENSINO FOCO SURDO OUVINTE RESPONSÁVEL ORGANIZAR MAS DESPREZA PROCONCEITO PESSOA OUVINTE SURDO MENTE TAMBÉM PROFISSÃO BOM NÃO PESSOA ACHAR SURDO AJUDAR NÃO SOCIEDADE AVANÇAR HABILIDADE NÃO TER PESSOA SURDO POSSÍVEL NÃO NÓS OBSERVAMOS/VEMOS FOCO ENSINO PORTUGUÊS OUVINTE ORALIZAR BOM PROGRESSO LIBRAS FALTAR SURDO APRENDER IGUAL IMPOSSÍVEL INCLUSÃO SURDO NÃO TER FALHAR VER CONTEÚDO TEMA DIVERSOS ENSINO ADAPTA SURDO FALTAR DEFEITOS MUITOS ENTÃO ARTIGO MOSTRAR MÉTODO PROPOSTA ENSINO PORTUGUÊS APLICA FOCO MOSTRAR DIVERSOS MATERIAIS/COISAS AJUDA INCLUSÃO SURDO POSSÍVEL

\section{SINAL PRINCIPAL LIBRAS PORTUGUÊS L2 ESTRATÉGIAS PEDAGOGIA APRENDER}

Vemos que o texto do sujeito 1 está construído seguindo contingências que são próprias da gramática da Língua Brasileira de Sinais, embora, saibamos que ao tentar transpor as informações para o plano gráfico, percamos boa parte da riqueza de detalhes do texto que foi elaborado para ser visto, numa língua visual espacial. Todavia, é possível fazermos uma análise do processo de retextualização ocorrido, uma vez que o sujeito utilizou estratégias para a composição de seu texto e essas estratégias são perceptíveis ao visualizarmos essa "tradução literal" e ao compararmos ela com o texto-fonte que subsidiou a retextualização.

No Quadro 3, a seguir, mostramos os dois textos lado a lado, a fim de fazermos uma comparação entre as informações do texto-fonte e as informações do texto retextualizado:

4. A "tradução literal" foi feita com a ajuda de um intérprete de Libras, que viu o vídeo com o texto sinalizado em Libras e traduziu para o português sinal por sinal. 
Quadro 4. Comparativo entre informações do texto principal e do texto sinalizado

\begin{tabular}{|c|c|}
\hline coes do texto-base & Informações do texto rete \\
\hline $\begin{array}{l}\text { Adequações do ensino do português como } \\
\text { L2 nas crianças surdas: um desafio a superar/ } \\
\text { enfrentar }\end{array}$ & $\begin{array}{l}\text { TEMA (TÍTULO) } \\
\text { CRIANÇAS SURDAS ENSINAR } \\
\text { PORTUGUÊS L2 AQUISIÇÃO DIFÍCIL } \\
\text { MAS EVOLUIR CONSEGUIR POSSÍVEL }\end{array}$ \\
\hline Marisa Dias Lima & $\begin{array}{l}\text { PESSOA ESCREVER NOME } \\
\text { M-A-R-I-S-A D-I-A-S L-I-M-A }\end{array}$ \\
\hline & NOME INTÉRPRETE .... \\
\hline $\begin{array}{l}\text { Resumo: A história do povo surdo revela que } \\
\text { por muitos séculos de existência, os aspectos } \\
\text { educacionais têm sido elaborados numa } \\
\text { perspectiva dos ouvintes e não dos surdos que, } \\
\text { quase sempre, são ignorados e desvalorizados } \\
\text { como sujeitos e profissionais que podem } \\
\text { contribuir a partir de suas capacidades inerentes } \\
\text { e de sua diferença: a de ser surdo }\end{array}$ & $\begin{array}{l}\text { PESQUISAR SURDO ENSINO PASSADO } \\
\text { HISTÓRIA ATÉ HOJE MOSTRA O QUE } \\
\text { ENSINO FOCO SURDO OUVINTE } \\
\text { RESPONSÁVEL ORGANIZAR } \\
\text { MAS DESPREZA PRECONCEITO } \\
\text { PESSOA OUVINTE SURDO MENTE } \\
\text { TAMBÉM PROFISSÃO BOM NÃO } \\
\text { PESSOA ACHAR SURDO AJUDAR NÃO } \\
\text { SOCIEDADE AVANÇAR HABILIDADE } \\
\text { NÃO TER }\end{array}$ \\
\hline $\begin{array}{l}\text { Desta maneira, a "integração/ inclusão" de } \\
\text { sujeitos } \\
\text { surdos nas escolas, tendo-se a língua oral e não a } \\
\text { LIBRAS como principal forma de comunicação, } \\
\text { faz-nos questionar se o seu conteúdo } \\
\text { metodológico ouvintista significa integrar o } \\
\text { surdo realmente. }\end{array}$ & $\begin{array}{l}\text { PESSOA SURDO POSSÍVEL NÃO } \\
\text { NÓS OBSERVAMOS/VEMOS FOCO } \\
\text { ENSINO PORTUGUÊS OUVINTE } \\
\text { ORALIZAR BOM PROGRESSO LIBRAS } \\
\text { FALTAR SURDO APRENDER IGUAL } \\
\text { IMPOSSÍVEL INCLUSÃO SURDO NÃO } \\
\text { TER FALHAR }\end{array}$ \\
\hline $\begin{array}{l}\mathrm{Na} \text { verdade, os seus conteúdos desenvolvidos } \\
\text { são basicamente uma suposição, "adaptação" } \\
\text { forçada para os surdos. }\end{array}$ & $\begin{array}{l}\text { VER CONTEÚDO } \\
\text { ENMA }\end{array}$ \\
\hline
\end{tabular}




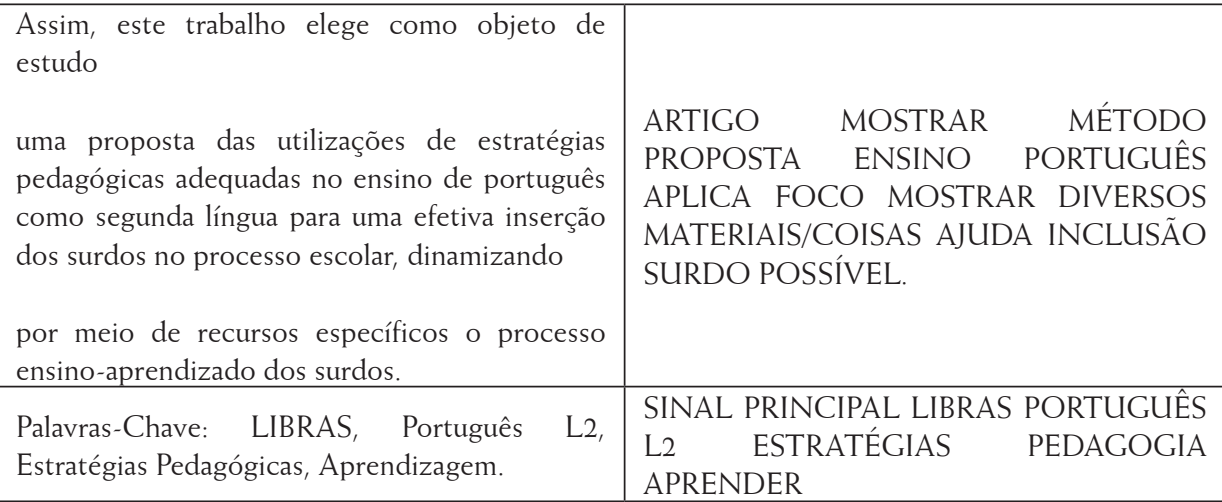

Ao compararmos as informações dos dois textos, vemos que o texto retextualizado se aproxima mais da retextualização como transformação, conforme é discutida em Marcuschi (2010 [2000]), muito embora este autor não se reporte à retextualização como tradução. As diferenças na organização das informações nos dois textos são evidentes. A forma como as palavras estão organizadas em um e em outro texto aponta que o texto retextualizado se aproxima, aqui, mais de uma interpretação feita pelo surdo a partir de sua leitura do texto em português e se distancia sobremaneira de uma tradução propriamente dita.

Informações do texto-fonte que são mais fáceis de entender, como o título, aproximam-se mais do que aparece no texto retextualizado. Vemos que o título "Adequações do ensino do português como L2 nas crianças surdas: um desafio a superar/enfrentar" reaparece na retextualização como "TEMA (TÍTULO) CRIANÇAS SURDAS ENSINAR PORTUGUÊS L2 AQUISIÇÃO DIFÍCIL MAS EVOLUIR CONSEGUIR POSSÍVEL". O sujeito acrescenta na retextualização o sinal para TEMA/TÍTULO e, em seguida, sinaliza o título, porém, como já é próprio da língua de sinais, não entram na retextualização elementos do português como conjunção, preposição e artigo, como o "do", o "como", o "nas", o "um" e o "a".

Para esta porção de informação que abarca o título do texto-fonte, as estratégias de retextualização mais evidentes são a substituição e a reordenação, que são utilizadas, basicamente, para adaptação da informação à Libras, que não é organizada como o português e não tem o mesmo léxico. Dessa forma, a informação expressa a partir da palavra "desafio", em português, é sinalizada a partir de "AQUISIÇÃO DIFÍCIL MAS...", que se liga a uma interpretação que pode ser feita em língua de sinais da informação expressa a partir do vocábulo, em língua portuguesa, "desafio". Então, a informação do trecho "um desafio a superar/ 
enfrentar", em português, reaparece sinalizada como "AQUISIÇÃO DIFÍCIL MAS EVOLUIR CONSEGUIR POSSÍVEL".

Em seguida à apresentação de informações relacionadas ao título, é feito um acréscimo de informação, antes da indicação do nome da autora do texto. Então, é sinalizado "PESSOA ESCREVER ARTIGO" e, em seguida, feita a datilologia do nome da autora. Após o nome da autora, é feito mais um acréscimo, para identificar o intérprete, no caso o sujeito sinalizador, "NOME INTÉRPRETE", e, em seguida, feita a datilologia do nome ${ }^{5}$. O interlocutor ou aquele que vê o texto precisa dessas informações acrescentadas, que são necessárias, uma vez que, no texto sinalizado, as informações que seriam interpretadas pelo aspecto gráfico (como o título em caixa alta e centralizado, o nome do autor alinhado à direita etc.) precisam ser informadas.

Semelhante ao que acontece com a retextualização de informações do título, acontece com as informações do texto retextualizado que estão relacionadas ao primeiro período do resumo acadêmico. Conforme podemos observar no Quadro 5, a seguir, o sujeito utiliza principalmente estratégias de reordenação e substituição de elementos linguísticos, para dizer, em língua de sinais, o seu entendimento do texto em português. Neste ponto, o texto retextualizado se distancia de uma tradução e se mostra mais como um texto construído a partir de um primeiro que, na verdade, apresenta mais o que o sujeito entende/interpreta do texto-base, sem a preocupação de se limitar ou de reapresentar as ideias do texto-fonte:

Quadro 5. Comparação de informações do resumo e da retextualização

\begin{tabular}{|c|c|}
\hline $\begin{array}{l}\text { Resumo: A história do povo surdo revela que } \\
\text { por muitos séculos de existência, os aspectos } \\
\text { educacionais têm sido elaborados numa } \\
\text { perspectiva dos ouvintes e não dos surdos que, } \\
\text { quase sempre, são ignorados e desvalorizados } \\
\text { como sujeitos e profissionais que podem } \\
\text { contribuir a partir de suas capacidades } \\
\text { inerentes e de sua diferença: a de ser surdo }\end{array}$ & 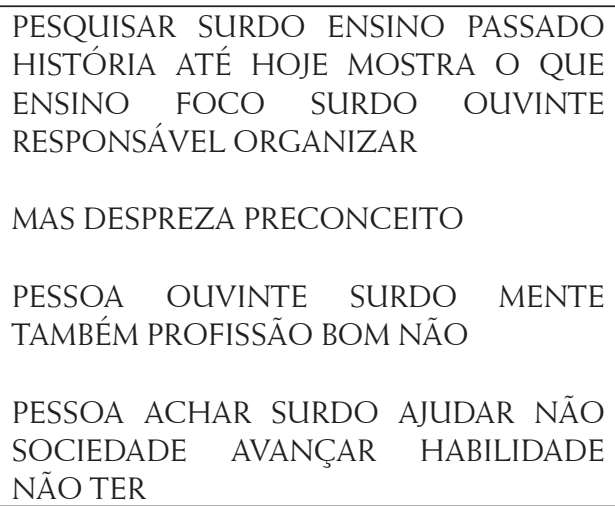 \\
\hline
\end{tabular}

5. Os nomes dos sujeitos foram omitidos por razões éticas. 
Nos dados do Quadro 5, vemos que o sujeito compreendeu o texto-fonte, dizendo que as pesquisas sobre ensino de surdos, do passado até hoje, mostram que o ensino de surdo tem como foco o ouvinte, que é o responsável por organizar esse ensino, mas que despreza o surdo e tem preconceito com este, acreditando que ele não pode ter uma profissão, não pode ajudar a sociedade, porque não tem habilidades. Logo, há uma relação direta da informação do texto em Libras com o texto em português, mas, além de substituições e acréscimos, o sujeito faz eliminações de informações do texto-fonte. A eliminação pode ter acontecido por o sujeito julgar desnecessárias ou menos importantes algumas informações, por acreditar que as informações já apontadas sejam suficientes para apresentar o sentido do texto original, por não ter conseguido dizer em Libras todas as informações do texto em português ou, ainda, por o sujeito não compreender parte das informações do texto-fonte.

As considerações acerca do primeiro período do resumo acadêmico retextualizado valem também para o modo como a informação é retextualizada nos períodos seguintes, em que as informações mais gerais se sobrepõem às informações mais localizadas, prevalecendo o sentido apresentado pelo todo textual. É possível perceber a partir desse caso que a retextualização apresenta o sentido global do texto, embora o sujeito surdo não tenha conhecimentos de língua portuguesa suficientes para fazer uma leitura detalhada, informando sobre o que trata cada parte do resumo.

Importante ressaltar que, na retextualização das palavras-chave, basicamente não houve transformação. Como as palavras-chave consistem apenas numa sequência de palavras, sem a necessidade de uma organização sintática, houve correspondência aos sinais, em Libras, que mais se aproximavam ao sentido das palavras-chave do texto-fonte. O sinal que substitui a palavra "pedagógicas", no português, é o mesmo de "PEDAGOGIA", em Libras, que se refere a todas as variações morfológicas desse vocábulo do português. Ao se referir a "aprendizagem", o sujeito faz uma substituição e sinaliza "APRENDER", sem fazer a derivação morfológica que outros sujeitos usuários de língua de sinais fazem quando se referem, em Libras, especificamente à "APRENDIZAGEM".

Esse tipo de adaptação contingencial à língua alvo é notória ao longo da retextualização feita pelo sujeito surdo, que considera os aspectos formais do gênero resumo acadêmico. São ressaltados o título, o nome do autor, o resumo e as palavras-chave, o que evidencia que o surdo compreendeu a composição formal do gênero. As substituições, reordenações, eliminações e acréscimos feitas ao longo 
da retextualização do corpo do resumo, auxiliam o sujeito a apresentar, no texto sinalizado, o sentido global do texto em português.

É relevante considerar que, para a construção da retextualização e para a leitura do texto em português, o sujeito surdo 1 teve a ajuda de outros colegas de turma que são ouvintes bilíngues, com domínio de língua portuguesa e de Libras. Logo, esses colegas ouvintes ajudaram o surdo também na escolha dos sinais para a composição do texto sinalizado. Percebemos, no entanto, que, ao final do processo, o sujeito compreendeu o sentido do texto em português e ainda o sentido do que sinalizou em Libras.

Já, no Quadro 6, a seguir, mostramos a tradução literal do texto sinalizado pelo sujeito surdo 2, que também tem dificuldades com a língua portuguesa, mas que fez sozinho, apenas com o apoio do dicionário, a leitura do texto em português:

Quadro 6. Glosa do texto sinalizado pelo sujeito surdo 2

COMO? TEMA PORTUGUES SEGUNDA LINGUA CRIANÇA ENSINAR PRÓPRIO SURDO ABSORVER/AQUISIÇÃO DESAFIO

COMO? PESSOA MULHER A-U-T-O-R-A M-A-R-I-S-A D-I-A-S L-I-M-A

"TEMA"

MUITO TEMPO PASSADO HISTÓRIA SURDO PRÓPRIO SEPARADO DO QUE SURDO OUVINTE VER MENOSPREZAR HUMILHAR /COMO?/ QUAL TEMÁTICA CARACTERÍSTICA, /COMO?/ SOFRER, NÃO PRECISAR SEMPRE QUASE ALGUNS POUCOS PRECISA PRECONCEITO SENTIR JEITO PROFESSOR SEPARAR IMPOSSÍVEL DIFERENTE SURDO PRÓPRIO /COMO?/ UNIÃO COMPLEMENTO DAQUI ESCOLA EXPERIÊNCIA COMO LÍNGUA ORAL NÃO, LÍNGUA ORAL NÃO, LIBRAS! PRINCIPAL FALHA COMUNICAÇÃO O QUE PROPOSTA LÍNGUA 1 FAZER O QUE FALAR SURDO PRÓPRIO VERDADE METODOLOGIA UNIÃO DESENVOLVIMENTO RETROCEDER OPINIÕES ADAPTAR ESFORÇO SURDO PRÓPRIO DEFESA APLICA, ESTUDAR, OFÍCIO PROPOSTA USAR ESTRATÉGIA PEDAGOGIA, PROPOSTA ENSINAR PORTUGUÊS L2 INTERNO SURDO SALA, ESCOLA, DEFENDE SALA, SALAS DEFENDE VOLTADO/ FOCO, VOLTADO/FOCO DIMINUIR AJUDA APRENDER, APRENDER PORTUGUÊS ESTRATÉGIA PEDAGOGIA SURDO PRÓPRIO.

Vemos que, já na retextualização do título do texto-fonte, o sujeito surdo 2 faz mais transformações das informações que o sujeito surdo 1. O sujeito 2 inicia a sinalização fazendo o sinal de "COMO(?)", como se interrogasse, marca linguística que se repete por algumas vezes ao longo da sinalização. Entendemos que isso esteja relacionado à própria forma de sinalizar ou estilo do sinalizador, sendo possivelmente equivalente a uma marca linguística que vemos na comunicação oral de algumas pessoas, como um informal "Aî" ou um mais formal "Então". Por 
outro lado, a palavra "como" aparece no título do texto em português, porém sem a indicação interrogativa sinalizada pelo sujeito surdo 2 .

Neste segundo caso, o sujeito surdo 2 também separa o título, a autora, que é apresentada como a "PESSOA MULHER", e, em seguida, faz a datilologia da palavra "A-U-T-O-R-A" e do nome "M-A-R-I-S-A D-I-A-S L-I-M-A". As informações do corpo do texto-fonte se distanciam do que é apresentado na sinalização, especificamente, embora ainda estejam relacionadas ao sentido do resumo de um modo geral.

Mostramos o vídeo para um intérprete de Libras e pedimos para que ele fizesse uma interpretação da sinalização do sujeito surdo, "dando voz" a este. Para que a interpretação não fosse influenciada, nós não mostramos inicialmente para o intérprete o texto em português, somente a retextualização. $\mathrm{O}$ quadro 7 , a seguir, mostra a interpretação feita pelo intérprete ${ }^{6}$ :

\section{Quadro 7. Interpretação feita pelo intérprete do vídeo do sujeito surdo 2}

\section{Título: O DESAFIO DA AQUISIÇÃO LÍNGUA PORTUGUESA COMO L2 PARA CRIANÇAS SURDAS}

\section{A MULHER AUTORA É MARISA DIAS LIMA}

Historicamente, o surdo tem sofrido uma separação, tem sofrido um desprezo, como uma classe inferior. Isso se mostra por várias razões, eles não precisavam ser salvos [eram poucos que poderiam está no meio dos ouvintes, "que conseguiam se desenvolver"] ${ }^{1}$. Eles eram desprezados, colocados à margem. Na escola, não havia essa união entre professores e surdos, era até impossível com tanta diferença [havia diferenças com o aluno surdo]. Para complementar, a escola tinha experiência com a língua oralizada, não era em libras, que é a principal, o que promove a falha na comunicação [impossível se comunicar]. Então, poderia se fazer uma proposta para se oficializar uma metodologia de ensino para surdos, para que haja um progresso e não um retrocesso, argumentos que se adaptem a realidade do surdo, a esse esforço do surdo, um ofício [documento?], uma proposta para que se use métodos pedagógicos, uma proposta para o ensino de português como L2, para que se internalize [inclua?] o surdo dentro da escola, na sala de aula, para se manter o foco. Não diminuir, para que possa ajudar o surdo a aprender português. Então é preciso ter essas estratégias pedagógicas para ajudar o surdo.

Quando nos deparamos com o texto do intérprete, vimos que já tínhamos ali, de fato, a retextualização da retextualização, de modo que fica claro o rearranjo que é feito pelo profissional, tanto para construção do texto em português quanto para organizar o pensamento expresso no texto sinalizado pelo surdo. $\mathrm{Na}$ retextualização do intérprete, são notórios os vários acréscimos de informações que são feitos a partir de pistas linguísticas que aparecem na retextualização do surdo.

6. Enquanto o intérprete via o vídeo, íamos digitando o que ele falava, talvez por isso o texto apresente alguns truncamentos, haja vista que ele fez uma tradução simultânea. 
O sujeito surdo 2 acrescentou a sua retextualização informações que interpretou estarem relacionadas à temática do texto-fonte, já o intérprete acrescentou a sua interpretação informações que percebeu estarem relacionadas ao pensamento apresentado pelo surdo ao longo da sua sinalização. Ambos os sujeitos, o surdo e o intérprete, identificaram pistas linguísticas no texto a ser retextualizado e as utilizaram em favor do seu projeto de texto.

Ao vermos o texto-fonte, a retextualização do surdo e a retextualização do intérprete, deparamo-nos com três textos que não dizem a mesma coisa, muito embora estejam ligados ao mesmo tema: ensino de português como segunda língua para crianças surdas. Esse dado nos permite discutir um aspecto importante acerca da retextualização analisada com textos em língua de sinais, mais precisamente em relação à produção textual dos surdos. Embora falte ao sujeito um aspecto fundamental na tradução, que é o domínio das duas línguas envolvidas no processo tradutório, ainda assim há a retextualização e a produção textual acontece.

$\mathrm{Na}$ análise comparativa da retextualização dos sujeitos surdos 1 e 2, vemos que em ambos os casos existe uma interpretação possível do texto-fonte, ainda que não haja, na retextualização, a apresentação de informações pontuais do texto-fonte, especialmente aquelas localizadas no corpo do texto. Dessa forma, temos, nos casos que analisamos, uma retextualização que se aproxima mais da que é apresentada em Marcuschi (2010 [2000]), como transformação, do que em Travaglia (2013), como tradução, muito embora se trate de uma retextualização envolvendo duas línguas.

Os dados que analisamos do processo de leitura de textos em português por sujeitos surdos com conhecimento em Libras e com noções de língua portuguesa na modalidade escrita sinalizam que: 1) A retextualização que mais se aproxima do texto-fonte, preservando as informações, é aquela feita de partes mais simples, como título, nome do autor, palavras-chave, que, em separado do corpo do texto, são de mais fácil entendimento; 2) A retextualização da parte que compreende o corpo do texto aconteceu a partir de uma estratégia de leitura que captura apenas a ideia geral do resumo, uma vez que o encadeamento sintático das orações e períodos em português tornam a leitura mais difícil para o sujeito que tem pouco conhecimento em língua portuguesa.

Ademais, a análise dos dados mostrou que o sujeito surdo 1, que teve auxílio de ouvintes fluentes em português e em Libras, conseguiu se aproximar mais do sentido apresentado pelo texto escrito em português, embora também tenha considerado o sentido global deste. O texto sinalizado em Libras pelo sujeito surdo 1 também mostrou mais coerência na escolha e disposição de sinais, para a construção de sentido. 
Já a análise do texto do sujeito surdo 2, que não teve auxílio de ouvintes fluentes em português e em Libras, mostrou que a elaboração de sentido textual também aponta para uma construção global, formada a partir do que o sujeito conseguiu compreender com a leitura feita apenas com a ajuda do dicionário. Essa construção fez uso, além das estratégias de eliminação substituição e reordenação, também de acréscimos de informações, supostamente, elencadas a partir do conhecimento de mundo do sujeito e interpretadas como estando relacionadas à temática apresentada no texto-fonte.

Os resultados sinalizam ainda para a importância de o professor que tem alunos surdos trabalhar em favor de ampliar os conhecimentos linguísticos de português desses alunos, favorecendo a leitura de textos em português aliada à expressão da compreensão desses textos em Libras. Este trabalho se mostra mais produtivo quando a leitura de textos em português por surdos é orientada pelo professor ou por estudantes bilíngues.

Não temos espaço para discutir aqui, mais detalhadamente, os acréscimos de informações, que são feitos rapidamente pelo intérprete, simultaneamente à comunicação, na tentativa de organizar o pensamento expresso pelo surdo e de dizer algo que tenha sentido para as pessoas para quem ele interpreta. Todavia, vemos que esse processo especificamente dá margem para uma investigação mais cuidadosa das estratégias utilizadas pelo intérprete para "dar voz" ao sujeito surdo.

\section{CONSIDERAÇÕES FINAIS}

A retextualização feita nas informações do texto-fonte está vinculada à interpretação feita desse texto pelo surdo, que, normalmente, tem em vista a porção textual como um todo representativo de um sentido capturado pelo sujeito a partir de pistas linguísticas. Assim, com a análise dos dados, reafirmamos nosso pensamento inicial acerca da retextualização feita por surdos da graduação, uma vez que as estratégias utilizadas na retextualização de texto escrito em português para Libras estão vinculadas à estrutura da língua alvo, que é a Libras. A interpretação que o surdo faz do texto principal está ligada, dentre outros fatores, a sua forma de se relacionar com o mundo, a partir de sua língua materna, e ao seu conhecimento em língua portuguesa.

Nossos resultados podem nos conduzir a outros caminhos de análise além do trabalho com a retextualização como ferramenta didática. Podemos, ainda, pensar outras estratégias que levem o surdo a leituras mais detalhadas de texto em português, que se atenham ao que é apresentado por cada parte, para a construção 
do sentido do todo textual, uma vez que na graduação não há mais tempo hábil de se trabalhar o ensino de língua, conforme deve ser feito no ensino básico. Porém, precisamos pensar em estratégias que ajudem os alunos surdos a ler em português, porque precisamos desse conhecimento, para desenvolvermos satisfatoriamente nosso trabalho em sala de aula.

Ademais, existem muitas práticas, envolvendo o uso linguístico por surdos, tanto de Libras como de português, que podem ser analisadas a partir da noção de retextualização, que ainda podem ser aliadas à noção de gêneros textuais, de letramentos etc. Como já disse Marcuschi (2010 [2000]), há variáveis importantes que podem ser consideradas no processo de retextualização que, evidentemente, são levadas em consideração pelo usuário da língua na produção de seus textos, na retextualização em situações de fala e escrita: o propósito ou o objetivo da retextualização, a relação entre o produtor do texto original e o transformador, a relação tipológica entre o gênero textual original e o gênero da retextualização e os processos de formulação típicos de cada modalidade da língua. Entendemos que essas variáveis apontadas por Marcuschi, especialmente, para a transformação da fala em escrita, podem, evidentemente, ser pensadas na transformação de escrita em fala ou entre textos escritos, mas ainda em relação à transformação de escrita em textos sinalizados e vice-versa. Algo que nos direciona para pesquisas futuras.

Ao começarmos a ministrar aulas para surdos, no ensino superior, vimos que tínhamos a necessidade de fazer com que os alunos reconhecessem, lessem e escrevessem os gêneros acadêmicos. Ao mesmo tempo nos deparamos com a dificuldade: como trabalhar leitura e escrita de textos em português com alunos cuja Libras é a língua materna e que não conhecem suficientemente o português? A ideia de desenvolver uma atividade com a produção do vídeo-registro surgiu como uma forma de se trabalhar a leitura em português, com a produção textual em Libras, e de motivar a prática de leitura dos alunos, trazendo um texto em português que tratava da própria realidade deles. Somente a partir dos vídeos produzidos pelos alunos, vimos que podíamos analisar as produções textuais à luz da própria noção teórica que nos apontou o caminho para o desenvolvimento da atividade em sala de aula.

\section{REFERÊNCIAS BIBLIOGRÁFICAS}

ABASSE, M. C. J. P. (2008). A produção do resumo escolar como resultado da atividade de retextualização. 2008. 137 f. Dissertação (Mestrado em Estudos Linguísticos) - Faculdade de Letras, Universidade Federal de Minas Gerais, Belo Horizonte. 
BEAUGRANDE, R.; DRESSLER, W. U. (1981). Introduction to text linguistics. London: Longman.

BRASIL. (2005). Decreto Federal n 5.626 de 22 de dezembro de 2005. Regulamenta a Lei no 10.436, de 24 de abril de 2002, que dispõe sobre a Língua Brasileira de Sinais Libras, e o art. 18 da Lei no 10.098, de 19 de dezembro de 2000. Diário Oficial da União, Brasília, DF, 2005.

LIMA, M. D. (2014). Adequação do ensino do português como $l 2$ nas crianças surdas: um desafio a superar/enfrentar. Disponível em: <http://2014.revistaintercambio.net.br/24h/ pessoa/temp/anexo/1/416/744.pdf > . Acesso em: 02 nov. 2014.

MALTA, J. O. O. (2008). O refinamento da competência textual discursiva através de processos de retextualização de narrativas de um conto tradicional. $165 \mathrm{f}$. Dissertação (Mestrado em Estudos Linguísticos) - Faculdade de Letras, Universidade Federal de Minas Gerais, Belo Horizonte.

MARCUSCHI, L. A. (2000). Da Fala para a Escrita: atividades de retextualização. 10. ed. São Paulo: Cortez, 2010.

MAREGA, L. M. P. (2009). A propósito da relação fala-escrita: um estudo comparativo da organização tópica de palestras e suas retextualizações. 186 f. Dissertação (Mestrado em Estudos Linguísticos) - Programa de /Pós-Graduação em Letras, Universidade Estadual de Maringá, Maringá.

MATA, M. A. (2008). Processos referenciais na retextualização de textos acadêmicos. $174 \mathrm{f}$. Tese (Doutorado em Estudos Linguísticos) - Faculdade de Letras, Universidade Federal de Minas Gerais, Belo Horizonte.

MILITÃO, J. A. (2007). Retextualização de textos acadêmicos: aspectos cognitivos e culturais. 230 f. Tese (Doutorado em Estudos Linguísticos) - Programa de Pós-Graduação em Estudos Linguísticos, Universidade Federal de Minas Gerais, Belo Horizonte.

PROJETO Pedagógico do Curso de Licenciatura Em Letras-Libras. Universidade Federal do Piauí, Teresina, 2014.

QUADROS, R. M.; KARNOPP, L. B. (2007). Língua de sinais brasileira [recurso eletrônico]: estudos linguísticos. Porto alegre: Artmed.

REVISTA Brasileira de Vídeo-Registro em Libras. Disponível em: http:// revistabrasileiravrlibras.paginas.ufsc.br/. Acesso em: 23 dez. 2017. 
SILVA, A. V. L. (2013). Com a palavra, o aluno: processos de retextualização na exposição oral acadêmica. 231 f. Tese (Doutorado em Estudos Linguísticos) - Programa de PósGraduação em Estudos Linguísticos, Universidade Federal de Minas Gerais, Belo Horizonte: UFMG.

SOUZA, S. X. (2010). Performances de tradução sobre a Lingua Brasileira de Sinais observadas no curso de Letras-Libras. Tese de Doutorado. Programa de Pós-Graduação em Estudos da Tradução: lexicografia, tradução e ensino de línguas estrangeiras. Universidade Federal de Santa Catarina: Florianópolis.

TRAVAGLIA, N. (1993). A tradução numa perspectiva textual. 315 f. Tese (Doutorado em Língua e Literatura Francesa) - Departamento de Letras Modernas, Universidade de São Paulo, São Paulo.

TRAVAGLIA, N. (2013). Tradução Retextualização: a tradução numa perspectiva textual. Uberlândia: EDUFU.

VIEIRA-BARBOSA, M. L. (2015). O processamento da informação na webnotícia. Tese de Doutorado. Programa de Pós-Graduação em Estudos Linguísticos. Faculdade de Letras - Universidade Federal de Minas Gerais: Belo Horizonte.

Recebido: 20/08/2017

Aceito: 04/01/2018 